JOURNAL OF SYNCHROTRON RADIATION

ISSN 1600-5775

Received 24 January 2019

Accepted 13 April 2019

Edited by M. Weik, Institut de Biologie Structurale, France

Keywords: X-ray radiation damage; free-radical radiation chemistry; macromolecular crystallography; DFT calculations; amino-acid side chains.

Supporting information: this article has supporting information at journals.iucr.org/s
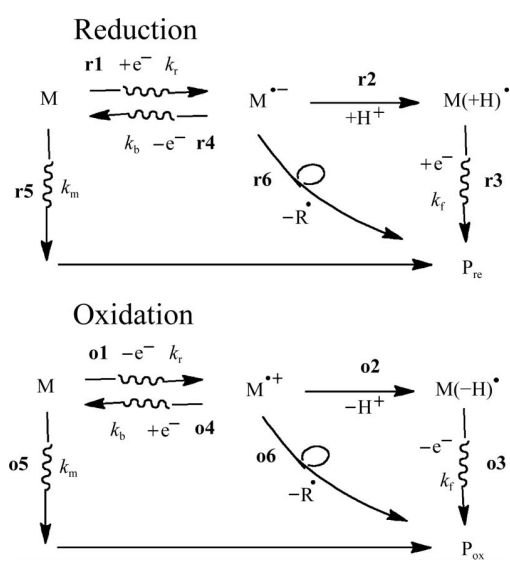

C 2019 International Union of Crystallography

\section{Comprehensive model for X-ray-induced damage in protein crystallography}

\author{
David M. Close ${ }^{a *}$ and William A. Bernhard ${ }^{b}$

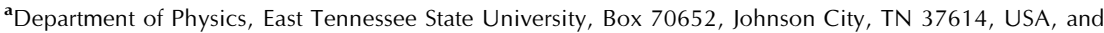 \\ ${ }^{\mathbf{b}}$ Department of Biochemistry and Biophysics, University of Rochester, Rochester, NY 14642, USA. \\ *Correspondence e-mail: closed@etsu.edu
}

Acquisition of X-ray crystallographic data is always accompanied by structural degradation owing to the absorption of energy. The application of high-fluency $\mathrm{X}$-ray sources to large biomolecules has increased the importance of finding ways to curtail the onset of X-ray-induced damage. A significant effort has been under way with the aim of identifying strategies for protecting protein structure. A comprehensive model is presented that has the potential to explain, both qualitatively and quantitatively, the structural changes induced in crystalline protein at $\sim 100 \mathrm{~K}$. The first step is to consider the qualitative question: what are the radiation-induced intermediates and expected end products? The aim of this paper is to assist in optimizing these strategies through a fundamental understanding of radiation physics and chemistry, with additional insight provided by theoretical calculations performed on the many schemes presented.

\section{Introduction}

Acquisition of X-ray crystallographic data is always accompanied by structural degradation owing to the absorption of energy. The application of high-fluency X-ray sources to large biomolecules has increased the importance of finding ways to curtail the onset of X-ray-induced damage. A significant effort has been under way with the aim of identifying strategies for protecting protein structure (Burmeister, 2000; Ravelli \& Garman, 2006; Ravelli \& McSweeney, 2000; Carugo \& Carugo, 2005; Carpentier et al., 2010). The aim of this paper is to assist in optimizing these strategies through a fundamental understanding of radiation physics and chemistry, with additional insight provided by theoretical calculations performed on the many schemes presented here.

A comprehensive model is presented that has the potential to explain, both qualitatively and quantitatively, the structural changes induced in crystalline protein at $\sim 100 \mathrm{~K}$. The first step is to consider the qualitative question: what are the radiationinduced intermediates and expected end products?

A generalized reaction scheme is presented in Fig. 1. It is based on the specific reaction scheme presented in a previous paper (Sutton et al., 2013) for cleavage of the $\mathrm{S}-\mathrm{S}$ bond in lysozyme, as observed by X-ray diffraction, linked to formation of the $\mathrm{SS}^{\bullet-}$ radical anion, as observed by electron paramagnetic resonance (EPR). It is important to point out that in this previous paper the scheme presented to explain the $\mathrm{S}-\mathrm{S}$ bond cleavage involves two one-electron reductions.

A compendium of the radicals expected in proteins would include, for each amino acid and the peptide bond, the radicals produced by one-electron reduction (Fig. 2) and one-electron oxidation (Fig. 3). For the six most radiation-labile amino 
acids and the peptide bond, specific reaction schemes are given (Figs. 4-9). These are keyed to the general scheme in Fig. 1.

A continuation of this previous study was envisioned by William Bernhard. The next step was to look at the other common defects observed in X-ray crystallography. A broad

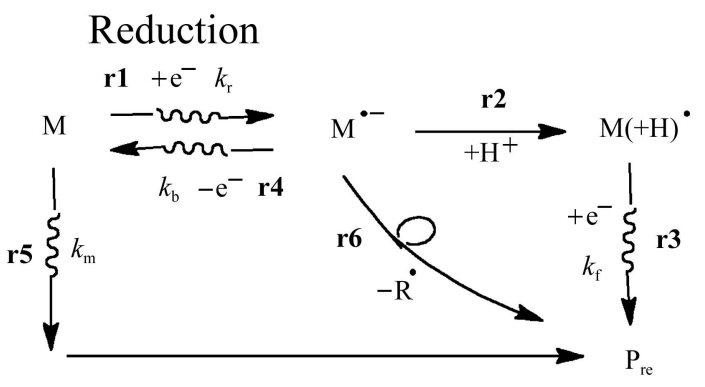

\section{Oxidation}

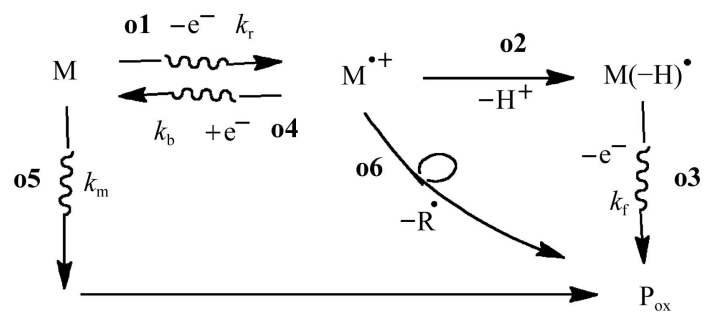

Figure 1

Generalized scheme for reactions initiated by the reduction and oxidation of protein component $\mathrm{M}$.
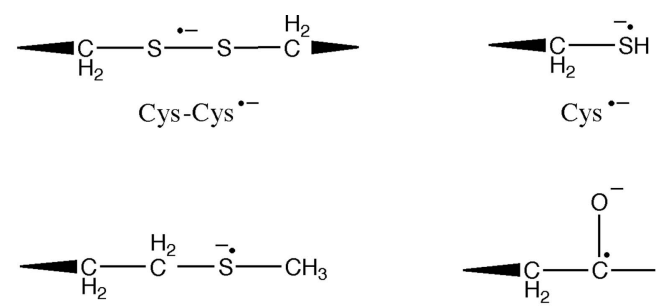

Met $^{\bullet-}$
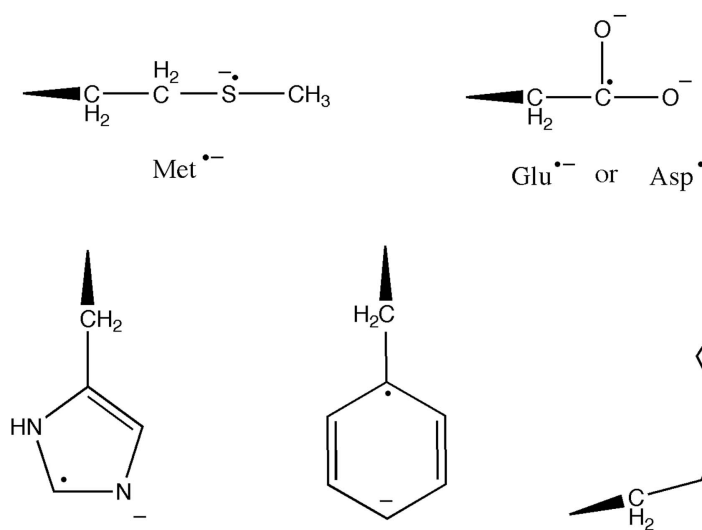

$\mathrm{Glu}^{\bullet-}$ or $\mathrm{Asp}^{\bullet-}$
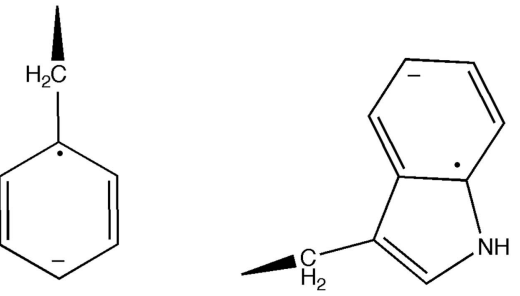

$\mathrm{His}^{\bullet-}$

$\mathrm{Phe}^{\bullet-}$

$\operatorname{Trp}^{\bullet-}$

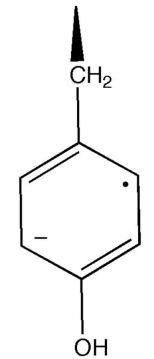

$\mathrm{Tyr}^{\bullet-}$

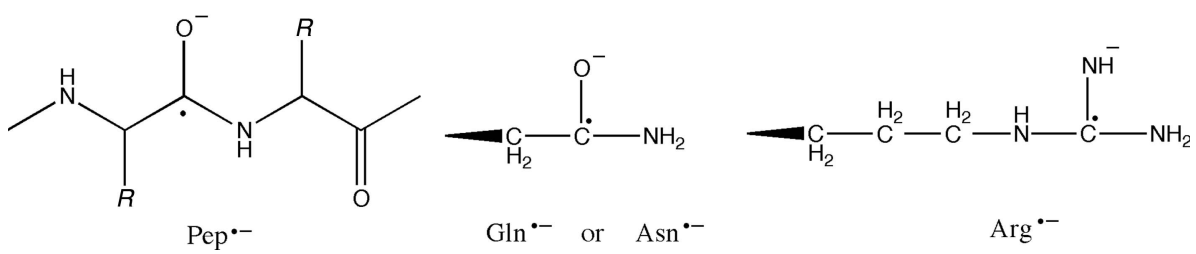

Figure 2

One-electron reduction is specific, occurring at sites with relatively high reduction potentials. outline of this process is presented. This work proposed the key steps necessary to produce the observed defects. However, some problems were obvious in the original outline. First of all, the key steps were taken from studies of amino acids. Protein crystallography deals with the side chains of the amino acids. It may be that the side chains of the amino acids will behave differently in a protein crystal than in a single crystal of an amino acid. A second problem comes from trying to understand which steps in the schemes presented here are energetically favorable. This can be ascertained by performing high-level calculations on model peptides. This is no trivial matter, as these calculations involve rather large models and can take several days to complete on a supercomputer.

\section{Qualitative aspects of the model}

\subsection{Generalized reaction scheme (Fig. 1)}

Ionizing radiation deposits energy via ionizations and excitations. All nucleobases involved in replication have very low fluorescence and phosphorescence quantum yields associated with excited-state lifetimes of the order of picoseconds, thereby selectively minimizing the chances of photochemical damage to the molecular building block in DNA (Kleinermanns et al., 2013). In protein crystals, however, tryptophan, tyrosine and phenylalanine possess fluorescent aromatic chromophores. The lifetimes of these excitations vary with the environment. The phosphorescence lifetime of tryptophan residues in proteins can vary from $3 \mathrm{~s}$ to microseconds (Gonnelli \& Strambini, 2005). The phosphorescence of tryptophan in proteins is effectively quenched by cystine, cysteine, histidine, tyrosine and by tryptophan itself (Kang et al., 2005). While there may be local environments in which some chromophores are not effectively quenched, in the present study it is assumed that damage owing to excitations is expected to be negligible in protein crystals.

One thing to note here is that irradiation with $\mathrm{X}$-rays is normally performed at low temperatures (typically $100 \mathrm{~K}$ ). Low temperatures minimize the diffusion of hydroxyl radicals, electrons and $\mathrm{H}$ atoms. This effectively eliminates the indirect effect. Thus, the direct effect of radiation will predominate in the present work. A discussion of direct effects versus indirect effects can be found in Bernhard \& Close (2003).

Starting with a neutral molecule $\mathrm{M}$ in Fig. 1, one-electron reduction gives a radical anion (reaction r1) and subsequent protonation $(\mathbf{r 2})$ converts it to a neutral radical. Both species, $\mathbf{M}^{\bullet-}$ and 
$\mathrm{M}(+\mathrm{H})^{\bullet}$, are referred to as one-electron reduction (1ER) sites. If a second track creates an ionization in the vicinity of a pre-existing electron-gain site, a second 1ER (r3) may occur. The result is a two-electron reduction product $\mathrm{P}_{\mathrm{re}}$. The second track may also generate a hole that adds to the electron-gain site, reaction $\mathbf{r} 4$, giving a back-reaction that regenerates $\mathrm{M}$.

One-electron oxidation gives a radical cation (reaction o1), and subsequent deprotonation (o2) converts it to a neutral radical, as shown at the bottom of Fig. 1. Both species, $\mathrm{M}^{\bullet+}$ and $\mathrm{M}(-\mathrm{H})^{\bullet}$, are referred to as holes or one-electron oxidation (1EO) sites. If a second track creates an ionization in the vicinity of a pre-existing hole, a second $1 \mathrm{EO}(\mathbf{o 3})$ may occur. The result is a two-electron oxidation product $\mathrm{P}_{\mathrm{ox}}$. The second track may also generate an electron that adds to the hole, reaction $\mathbf{0 4}$, giving a back-reaction that regenerates $\mathrm{M}$.

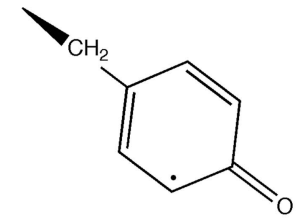

$\operatorname{Tyr}(\mathrm{O}-\mathrm{H})$

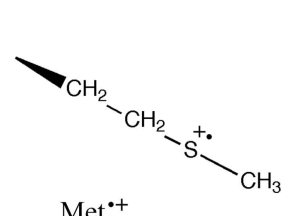

$\mathrm{Met}^{\bullet+}$

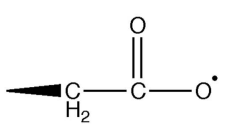

$\mathrm{Glu}^{\bullet+}$ or $\mathrm{Asp}^{\bullet+}$

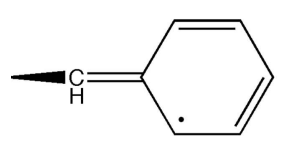

Phe $(\mathrm{C}-\mathrm{H})^{\cdot}$<smiles>CC(C)(C)C</smiles>

$\operatorname{Val}(\mathrm{C}-\mathrm{H})^{\bullet}$<smiles>CNC=CC(C)=O</smiles>

$\operatorname{Gly}(-\mathrm{H})$
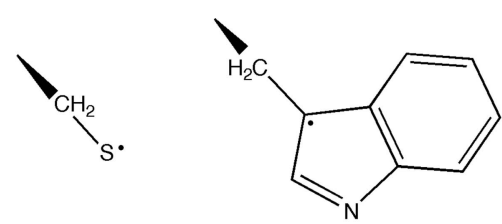

$\operatorname{Ser}(\mathrm{S}-\mathrm{H})^{\bullet}$
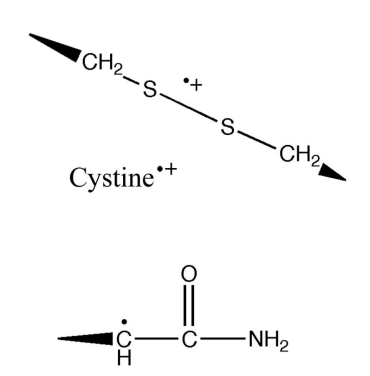

$\mathrm{G} \ln (\mathrm{C}-\mathrm{H})^{\bullet}$ or $\operatorname{Asn}(\mathrm{C}-\mathrm{H})^{\bullet}$
$\operatorname{Trp}(\mathrm{N}-\mathrm{H})^{\bullet}$
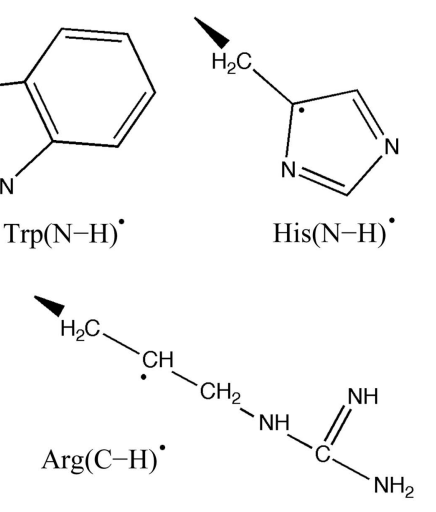

$\operatorname{His}(\mathrm{N}-\mathrm{H})^{\bullet}$

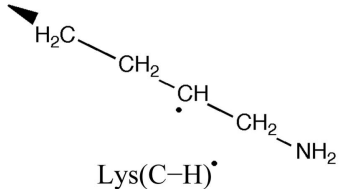

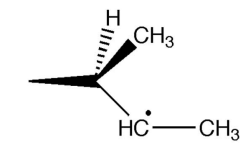

Ile $(\mathrm{C}-\mathrm{H})^{\bullet}$

$\operatorname{Pro}(\mathrm{C}-\mathrm{H})^{\bullet}$

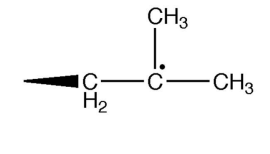

$\operatorname{Leu}(\mathrm{C}-\mathrm{H})^{\circ}$

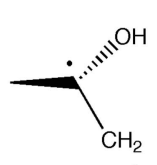

$\operatorname{Thr}(\mathrm{C}-\mathrm{H})^{\bullet}$

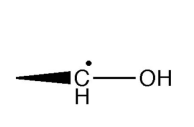

$\operatorname{Ser}(\mathrm{C}-\mathrm{H})^{\bullet}$

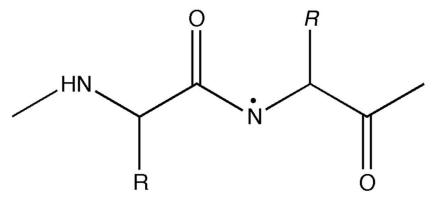

$\mathrm{Pep}(\mathrm{N}-\mathrm{H})^{\circ}$

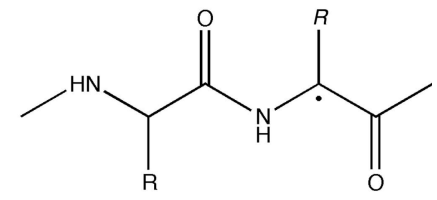

Pep(C-H)
Figure 3

A partial list of radicals produced by one-electron oxidation. The initial ionization is nonspecific, occurring at every site in the protein.
The majority of damage that can be detected by X-ray crystallography will occur by either two serial 1ERs or two 1EOs. For these pathways, the dose-dependent rate of $k_{\mathrm{b}}$ (the rate at which the radical goes back to the parent). It is important to note that these rates depend on the absorbed diation dose, not time. reactions entail two-electron reduction (2ER) and twoon oxidation (2EO), respectively. They occur within a be trapped. Products formed in this way are called st al., 2007) and are by definition not free radicals. The molecular reaction proceeds at a rate $k_{\mathrm{m}}$. The other is a unimolecular rearrangement of the radical intermediate, creating a radical plus a nonradical fragment (reactions $\mathbf{r 6}$ and o6). This type of reaction is relatively rare for organic molecules in the solid state at low temperatures.

Below, these two general schemes are applied to specific protein residues. In doing so, the reaction label given in the general scheme is used to label the reaction for specific residues. For example, reaction $\mathbf{5 . 0 3}$ refers to Fig. 5 and reaction $\mathbf{0 3}$ in Fig. 1.

\subsection{Radicals expected from one- electron reduction of protein (Fig. 2)}

It is known from EPR studies that sulfhydryls (Cys and Met), carboxylates (Glu and Asp) and aromatics (His, Phe, Trp and Tyr) are favorable sites for 1ER. Other 1ER sites, although less favorable, are the peptide bond, Gln, Asn and Arg. That is, of the 20 aminoacid residues, only 11 will compete effectively for capture of an electron (as shown in Fig. 2).

\subsection{Radicals expected from one-} electron oxidation of protein (Fig. 3)

The Bragg rule states that all of the protein constituents will be ionized with a relative probability that depends on the total number of electrons that make up the constituent. Initially, all of the residues and every peptide bond will sustain ionization with a probability governed by their electron number. Transfer of the hole from its initial site of formation to other sites is limited 
primarily by two types of reaction: (i) deprotonation, resulting in a net loss of hydrogen, and (ii) electron return. Deprotonation from carbon is generally irreversible and that from nitrogen or oxygen is reversible; both are possible for the peptide bond, as shown in Fig. $3[\operatorname{Pep}(\mathrm{N}-\mathrm{H})$ and $\operatorname{Pep}(\mathrm{C}-\mathrm{H})]$. Electron return restores the parent structure (back-reaction $\mathbf{o 4}$ in Fig. 1). Only four sites are expected not to deprotonate: Cys, Met, Glu and Asp.

There will be a preference for hole trapping at the sites of lowest oxidation potential; most noteworthy are Tyr, Cys, Trp, His and Met. Of particular interest are the neutral radicals produced from glutamate, aspartate and the peptide bond. All 20 residues, all peptide bonds, the amino-terminus and the carboxyl-terminus are potential hole traps. Furthermore, the larger residues contain more than one site capable of trapping a hole; for example, lysine can trap a hole by loss of an $\mathrm{H}$ atom from any of its four carbons. New results on the calculation of the standard reduction potentials of the amino acids incorporated in peptides have been presented (Close \& Wardman, 2018).

A major difference between hole trapping and excesselectron trapping is that the latter is significantly more specific than the former. While a residue such as tyrosine has a significant thermodynamic advantage for hole trapping, it must compete with a plethora of other sites. In contrast, cystine and cysteine have only a handful of other sites to compete with for electron addition.

\section{Theoretical methods}

The calculations that were performed followed the methods developed by Schlegel and coworkers on $N$-methyl-substituted DNA bases (Verdolino et al., 2008; Psciuk et al., 2012). Briefly, (i) the geometry of the dominant tautomer was optimized at the B3LYP/6-31+G(d,p) level of theory and frequencies were calculated, (ii) the gas-phase single-point calculation was conducted on the gas-phase optimized geometry at the B3LYP/AUG-cc-pVTZ level of theory and (iii) the geometry of each tautomer was optimized in aqueous solution at the $\mathrm{SMD} / \mathrm{B} 3 \mathrm{LYP} / 6-31+\mathrm{G}(\mathrm{d}, \mathrm{p})$ level of theory (Marenich et al., 2009) using the Gaussian 09 suite of programs (Frisch et al., 2013). Augmented AUG-cc-pVTZ calculations could not be used for the larger protein structures. The nature of the stationary points obtained was checked by calculating the analytic Hessians to ensure the absence of imaginary frequencies, indicating that at least local minima had been reached.

It is necessary to comment on the choice of basis sets used for these calculations. While it is true that one often obtains slightly different answers by using different basis sets, the interest here is in relative energies. For example, for the calculations presented here it is necessary to compare the electron affinity $(\mathrm{EA})$ of $\mathrm{B}(+\mathrm{H})^{\bullet}$ with the ionization potential (IP) of $\mathrm{B}^{\bullet-}$. While the differences in energies were substantial, the calculations seemed to be independent of the basis sets used (Close et al., 2013).
Excess-electron attachment to a polar molecule can produce two different types of anions: a valence-bound (VB) anion or a dipole-bound (DB) anion. For VB anions the extra electron occupies a valence molecular orbital and is strongly bound. DB electrons are weakly bound to polar molecules owing to electrostatic charge-dipole interactions and dispersion interactions, and therefore affect the molecular structure less than for valence-bound attachment. The use of density-function theory to perform calculations on DB anions suffers from the self-interaction error (Lee et al., 2010). A good summary of these two different types of anions is presented by Svozil et al. (2005).

In the present study, both valence-bound and dipole-bound anions are encountered. It is shown that the inclusion of a solvent [by solvent model density (SMD) calculations] can transform a dipole-bound anion into a valence-bound anion. It is evident from the literature that similar radicals on a protein can be found in very different environments. It is therefore important to examine SMD calculations in a variety of dielectric constants. When dipole-bound anions are encountered, attempts will be undertaken to convert them to valencebound anions since dipole-bound anions tend to overestimate electron affinities (Puiatti et al., 2008).

Four sets of calculations have been performed here. Firstly, the side chains of the amino acids studied are modeled with just the side-chain terminated with a methyl group (for example, the side chain of methionine was modeled as $\mathrm{CH}_{3}-\mathrm{S}$ $\mathrm{CH}_{2}-\mathrm{CH}_{2}-\mathrm{CH}_{3}$ ). It is important to know how the peptide backbone influences these calculations. Thus, a short peptide model such as $\mathrm{H}_{3} \mathrm{C}-\mathrm{NH}-\mathrm{CO}-\mathrm{CH}$ - $\mathrm{NH}-\mathrm{CO}-\mathrm{CH}_{3}$ was used (where $R$ is the side chain) and also a tripeptide, for example cysteine surrounded by alanine modeled as Ala-Cys-Ala. A few calculations were performed with a pentapeptide such as Ala-Ala-Cys-Ala-Ala.

In the conventions used here, the calculated energies are in hartrees, where one hartree equals $627.5095 \mathrm{kcal}$. The compared calculated hyperfine couplings are in megahertz or gauss (abbreviated $\mathrm{G}$ here); $1 \mathrm{MHz}=2.80247 \mathrm{G}$. For the energies listed in the schemes here the energies are ZPE (zero-point energy) corrected. Most of the hyperfine couplings cited are from older EPR/ENDOR experimental results; therefore, it is convenient to use gauss in this study. The pictures presented in the supporting information are in color, where blue represents positive spin density and green represents negative spin density.

\section{Specific reaction schemes for amino acids}

\subsection{Cystine}

Fig. 4 shows a reductive and an oxidative pathway for cystine that was previously used in the lysozyme paper (Sutton et al., 2013). A reductive pathway initiated by electron addition to $R \mathrm{SS} R$ (reaction 4.r1) gives a radical anion $\left(R \mathrm{SS} R^{\bullet-}\right)$ as observed by Akasaka et al. (1964) and also in detailed ENDOR experiments by Naito et al. (1976). If $R \mathrm{SS} R$ is coordinated with a favorable proton donor then proton 
transfer gives a neutral radical $R \operatorname{SS} R(\mathrm{H})^{\bullet}$, which is a reversible process. Subsequent proton transfer (4.r2) to this radical has been reported by Chan \& Bielski (1973). The driving force for this proton transfer is the change in the $\mathrm{p} K_{\mathrm{a}}$ in going from the neutral molecule to the radical anion $R \mathrm{SS} R^{\bullet-}$. Other experimental reports on thiyl radicals can be found in Wardman \& von Sonntag (1995) and Becker et al. (1988)

The neutral radical $R \mathrm{SS} R(\mathrm{H})^{\bullet}$ is itself a good electron trap. Thus, at higher doses a second one-electron reduction is likely (4.r3). This results in $\mathrm{S}-\mathrm{S}$ bond cleavage, yielding $R \mathrm{SH}$ and $R \mathrm{~S}^{-}$. Subsequent protonation of $R \mathrm{~S}^{-}$completes the formation of two cysteines from one cystine. Thus, $\mathrm{S}-\mathrm{S}$ bond cleavage is due to two one-electron reductions spawned by two separate tracks. The first track creates a radical anion and a second overlapping track adds another electron. However, the second track may also remove an electron (equivalent to adding a hole) via reaction 4.r4, regenerating the native structure. The reaction goes forwards via $4 . r 3$ and backwards via 4.r4.

Fig. 4 also has an oxidative pathway for disulfides. Reaction 4.o1 gives the radical cation $\left(R \mathrm{SS} R^{\bullet+}\right)$. This radical cation has previously been identified (Box et al., 1970; Box \& Freund, 1964; Bonifačić \& Asmus, 1978; Naito et al., 1976) at low temperatures. Upon warming, the EPR signal from the radical cation decays, suggesting that recombination of electrons and cations occurs. Stabilization of the cation radical by protonation has not been observed. Thus, a second one-electron oxidation (4.03) is unlikely. In this case, an overlapping second track will strongly favor the back-reaction 4.04 over the forward reaction 4.o3. By this reasoning, it was concluded that reduction, not oxidation, accounts for cleavage of the $\mathrm{S}-\mathrm{S}$ bond, as discussed previously (Sutton et al., 2013).

We thus return to the left-hand side of Fig. 4, which involves the reduction of cystine to produce the anionic radical $R S S R^{\bullet}$. This process is reversible. In crystalline lysozyme one sees elongation of the $\mathrm{S}-\mathrm{S}$ bond by up to $0.7 \AA$ upon reduction. A picture is given of the scheme proposed by Carpentier et al. (2010) for these steps, which appear to be the same as the first two steps in Fig. 4 here. These authors do not show the second one-electron reduction as outlined in Fig. 4 here.

Calculations on one-electron reduction of cystine have been performed to see whether these steps are energetically feasible. For the gasphase calculations, the anion is slightly more stable than the neutral molecule (small positive electron affinity). The same calculation in a dielectric medium (SMD) show even greater stability of the radical anion. The $\mathrm{S}-\mathrm{S}$ distance is calculated to be $2.0839 \AA$ for the neutral molecule (compared with the X-ray crystallographic value of $2.044 \AA$; Steinrauf et al., 1958). Upon the oneelectron reduction of cystine the calculated $\mathrm{S}-\mathrm{S}$ bond length is $2.934 \AA$, which is in agreement with the observations of Carpentier et al. (2010) as mentioned above (and shown in Supplementary Fig. S1).

The idea of a process involving a second one-electron addition comes from the fact that step 4.r2 involves a radical. The final products are usually neutral molecules. Furthermore, we know that the final product is simply two cysteines. This can easily be obtained with a second one-electron addition (4.r3) followed by protonation. It can be seen that the calculations show these steps to be energetically feasible (see Fig. 4).

The next step is to look at a model that includes cystine in a model peptide (Supplementary Fig. S2). Here, two short peptides are shown on the left (Supplementary Fig. S2a) and with the spin density for the cystine radical anion $R S S R^{\bullet-}$ on the right (Supplementary

Figure 4

Reductive (left column) and oxidative (right column) reaction pathways for cystine. The reaction numbers are keyed to Fig. 1: the $\mathbf{4}$ in reaction 4.r1 refers to Fig. 4 and the $\mathbf{r} \mathbf{1}$ refers to reaction $\mathbf{r} \mathbf{1}$ of Fig. 1. The numbers in bold are the calculated energies of each species in units of hartrees. 
Fig. S2b). It is interesting to note that the spin density in Supplementary Fig. S2(b) looks just like the spin density in Supplementary Fig. S1(c). Furthermore, both figures exhibit the same separation of the sulfurs.

As mentioned above, the process initiated by the buildup of the $R S S R^{\bullet-}$ radical anion was proposed by Carpentier et al. (2010). This intermediate may revert back to cystine, or the radical anion may protonate to yield $R \mathrm{SS} R(\mathrm{~S}+\mathrm{H})^{\bullet}$. This is fine, but they then suggest that $\mathrm{S}-\mathrm{S}$ bond cleavage occurs spontaneously from the radical anion or from the neutral protonated radical anion. It is more likely that the process proceeds by a second electron reduction as described in Fig. 4.

Another concern is the suggestion that the fractional occupancy of this radical anion is $<25 \%$ (Carpentier et al., 2010). A detailed calculation in Sutton (2013) suggests that this is more likely to be $\sim 2 \%$.

\subsection{Aspartate and glutamate}

Electron capture by the carboxyl group (5.r1) and its subsequent protonation (5.r2) have been well documented by Box and coworkers from studies of aspartic acid that detected the $\mathrm{Asp}^{\bullet-}$ radical in Fig. 5 (Adams et al., 1976). We posit that recombination with holes (5.r4) will be advantageous but that further reduction (5.r3) will not be.

Calculations of the reduction steps were performed on the short tripeptide with $-\mathrm{CH}_{3}$ (the side chain of alanine), then $-\mathrm{CH}_{2}-\mathrm{CO}_{2}$ (the side chain of aspartate) and then $-\mathrm{CH}_{3}$ (the side chain of alanine), again as shown in Supplementary Fig. S3( $a)$. One thing to note here is that the peptide backbone has been constrained to be flat. This is to avoid long optimizations involving the attractions between the backbone $\mathrm{N}-\mathrm{H}$ bonds and $\mathrm{C}=\mathrm{O}$ bonds that occur if one uses only short peptide chains. Calculations show that the first reduction followed by protonation to create the radical anion is favorable, but a further second reduction is unfavorable. Calculations do show that the return path 5.r2 to 5.r4 to create $\operatorname{Asp}(+\mathrm{H})^{+}$is favorable (Fig. 5).

One-electron oxidation is of more interest to X-ray crystallography as carboxylic acids are good hole traps, which leads to decarboxylation, as shown by Box et al. (1970) and by Sevilla et al. (1979). Decarboxylation of one-electron oxidized amino acids occurs at low temperatures, which suggests a very low activation energy. Indeed, Lipfert and coworkers have shown using DFT calculations that the decarboxylation of the $\mathrm{L}-O$-serinephosphate cation is a barrier-free process (Lipfert et al., 2004). A summary of
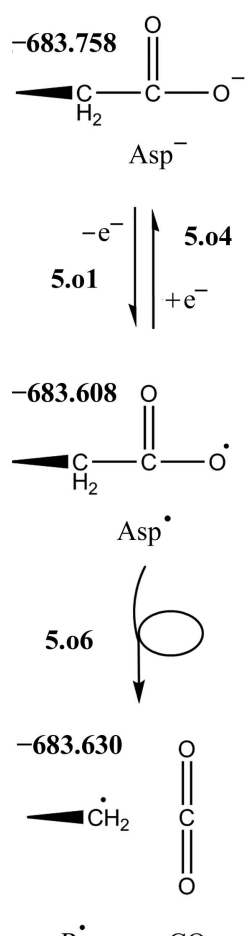

$\mathrm{R}^{\circ}$ these processes has been presented in a study of radiation damage to a co-crystal of formylglycine-cytosine including EPR (electron parametric resonance), ENDOR (electron nuclear double resonance), DFT (density functional theory) and low-temperature (10 K) irradiation (Sagstuen et al., 2006). In that study, a complete analysis of the decarboxylation of the neutral $N$-formylglycine oxidation product is presented.

One-electron oxidation (5.o1) results in a highly unstable oxyl radical that is not observed by EPR, even at $4 \mathrm{~K}$. A unimolecular reaction (5.06) gives rise to a neutral carboncentered radical $\left(-\mathrm{CH}_{2}^{\bullet}\right)$ plus $\mathrm{CO}_{2}$. There are numerous studies that cover the decarboxylation of one-electron oxidations of the amino acids (Øyen et al., 2014; Sagstuen et al., 2004; Strzelczak et al., 2007; Hidaka et al., 1997). It is seen that it is energetically favorable to form the neutral radical (5.06) by one-electron oxidation of the aspartate anion (5.04). Indeed, after just a few iterations the calculations show the loss of $\mathrm{CO}_{2}$. The calculations converged to a stationary point with a separation of $1.61 \AA$ (Supplementary Fig. S $3 a$ ). At this point the $\mathrm{CO}_{2}$ is not linear. Therefore, the separation was moved to $3.0 \AA$, as seen in Supplementary Fig. $\mathrm{S} 3(b)$. The $\mathrm{CO}_{2}$ is now linear. It is also seen that all of the spin density is on $-\mathrm{CH}_{2}^{\bullet}$, as predicted from Fig. 5 .

Also favorable will be the $1 \mathrm{EO}$ of $-\mathrm{CH}_{2}^{\bullet}(\mathbf{5 . 0 3})$ to give a carboanion $-\mathrm{CH}_{2}^{-}$. Thereby, $1 \mathrm{EO}$ of Asp gives the carboanion plus carbon dioxide. It needs to be pointed out that it would be difficult to detect this carboanion as it is not a radical and could not be detected by EPR.
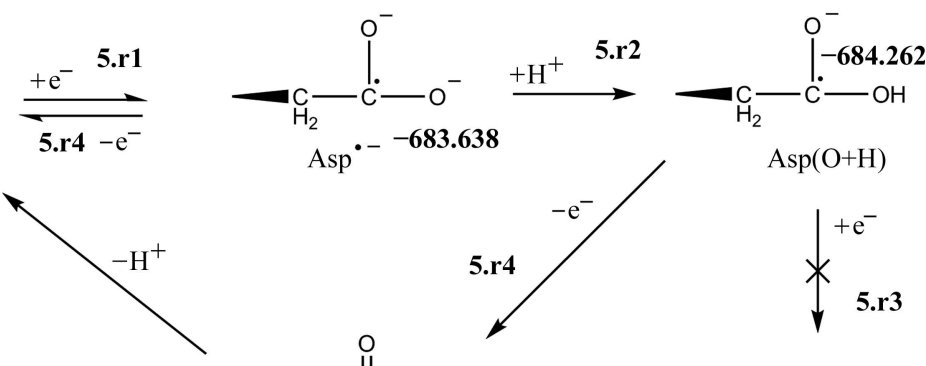

$\mathrm{Asp}^{\cdot-}-\mathbf{6 8 3 . 6 3 8}$
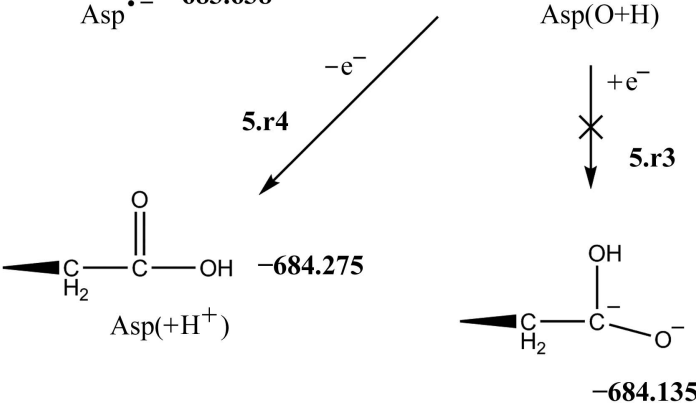

Figure 5

Reductive (top) and oxidative (left column) reaction pathways for aspartate. The corresponding reactions are just as likely for glutamate. The reaction numbers are keyed to Fig. 1: the $\mathbf{5}$ in reaction 5.r1 refers to Fig. 5 and the r1 refers to reaction $\mathbf{r 1}$ of Fig. 1. The numbers in bold are the calculated energies of each species in units of hartrees. 
Once again, calculations have been presented that aid in selecting between the oxidation or reduction pathway in Fig. 5. It seems that calculations favor the oxidation pathway. Also once again, the application of a second one-election oxidation is necessary to arrive at the experimentally observed products of a carboanion side chain and carbon dioxide.

\subsection{Tyrosine}

One-electron oxidation of tyrosine (6.01) gives $\mathrm{Tyr}^{\bullet+}$, which upon deprotonation (6.o2) gives the resulting neutral radical $\operatorname{Tyr}(\mathrm{O}-\mathrm{H})^{\bullet}$. This radical was studied by Box and coworkers in a detailed ENDOR experiment (Box et al., 1974). They report the two ortho ring protons to have isotropic hyperfine couplings of 6.2 G. Later, Sevilla and D'Arcy showed the EPR spectrum of the same radical to contain two ortho ring protons at $6 \mathrm{G}$, with one methylene proton at $6 \mathrm{G}$ and the other at $11 \mathrm{G}$ (Sevilla \& D'Arcy, 1978). A second one-electron oxidization (6.o3) will give a carbocation that may react with a neighboring water to give Ala plus 1,4-benzoquinone.

There are several concerns about the viability of this oxidative pathway. Calculations show some of these steps to be energetically feasible (Fig. 6). However, it is not clear that the carbocation in step $\mathbf{6 . 0 3}$ can react with a neighboring water molecule in a crystal at $100 \mathrm{~K}$. Also, the last step in this pathway requires a reorientation of the benzoquinone such that the oxygen is repositioned while leaving the cleavage of the $\mathrm{CH}_{2}$-phenol bond undetected.

One-electron reduction (6.r1) followed by protonation (6.r2) forms the $\operatorname{Tyr}(\mathrm{C}+\mathrm{H})^{\bullet}$ radical. This radical was characterized by Sevilla et al. (1979), with two hyperfine couplings of $45 \mathrm{G}$ at the ortho ring position and $12 \mathrm{G}$ at the meta ring position. An ENDOR study of tyrosine by Mezzetti et al. (1999) shows similar results. A second one-electron reduction (6.r3) followed by protonation would produce dihydrotyrosine.

Calculations were first performed on the tyrosine side chain, as shown in Supplementary Fig. S4. Firstly, it is noted that oneelectron reduction yields a radical anion with an energy near to that of neutral tyrosine. Some of the radical anions will therefore then revert back to neutral tyrosine, while some of the radical anions will protonate to yield the neutral tyrosine radical, which is a stable product. Also, we note that in Supplementary Fig. $\mathbf{S} 4(b)$ the tyrosine anion radical has a large dipole-bound anion. Supplementary Fig. S4(c) shows that repeating the calculation with a solvent (by SMD calculations with $\varepsilon=2.5$ ) can transform a dipole-bound anion to a valence-bound anion.

Next, calculations were performed on tyrosine in the shortpeptide model shown in Supplementary Fig. S5(a). Supplementary Fig. S5(b) shows the spin density for the radical anion. Here, there is still a small remnant of the dipole-bound anion, although in the short-peptide model the external dipole-bound lobe is greatly reduced. Supplementary Fig. S5(c) shows the ordinary valence-bound anion with almost all of the spin density on the tyrosine (again by SMD calculations with $\varepsilon=2.5$ ).
The radical anion (6.r1) will attract a proton that is added to the tyrosine ring, creating a neutral radical $\operatorname{Tyr}(\mathrm{C}+\mathrm{H})^{\bullet}(\mathbf{6 . r 2})$ The structure of the neutral radical is shown in Supplementary Fig. S6. A second one-electron reduction of the neutral radical creates the anion $\operatorname{Tyr}(\mathrm{C}+\mathrm{H})^{-}$. It can be seen that this is energetically feasible (Fig. 6). Again, this second one-electron reduction product bears a negative charge and will attract a proton, creating dihydrotyrosine, which is a neutral molecule. A structure is shown in Supplementary Fig. S6(c).

There are several noteworthy observations here. First of all, calculations on the one-electron loss lead to a dipole-bound anion, but this is easily converted to a valence-bond anion with a calculation involving the inclusion of solvent (SMD calculations, $\varepsilon=2.5$ ). Another observation involves the second oneelectron reduction. The interesting point is that the first
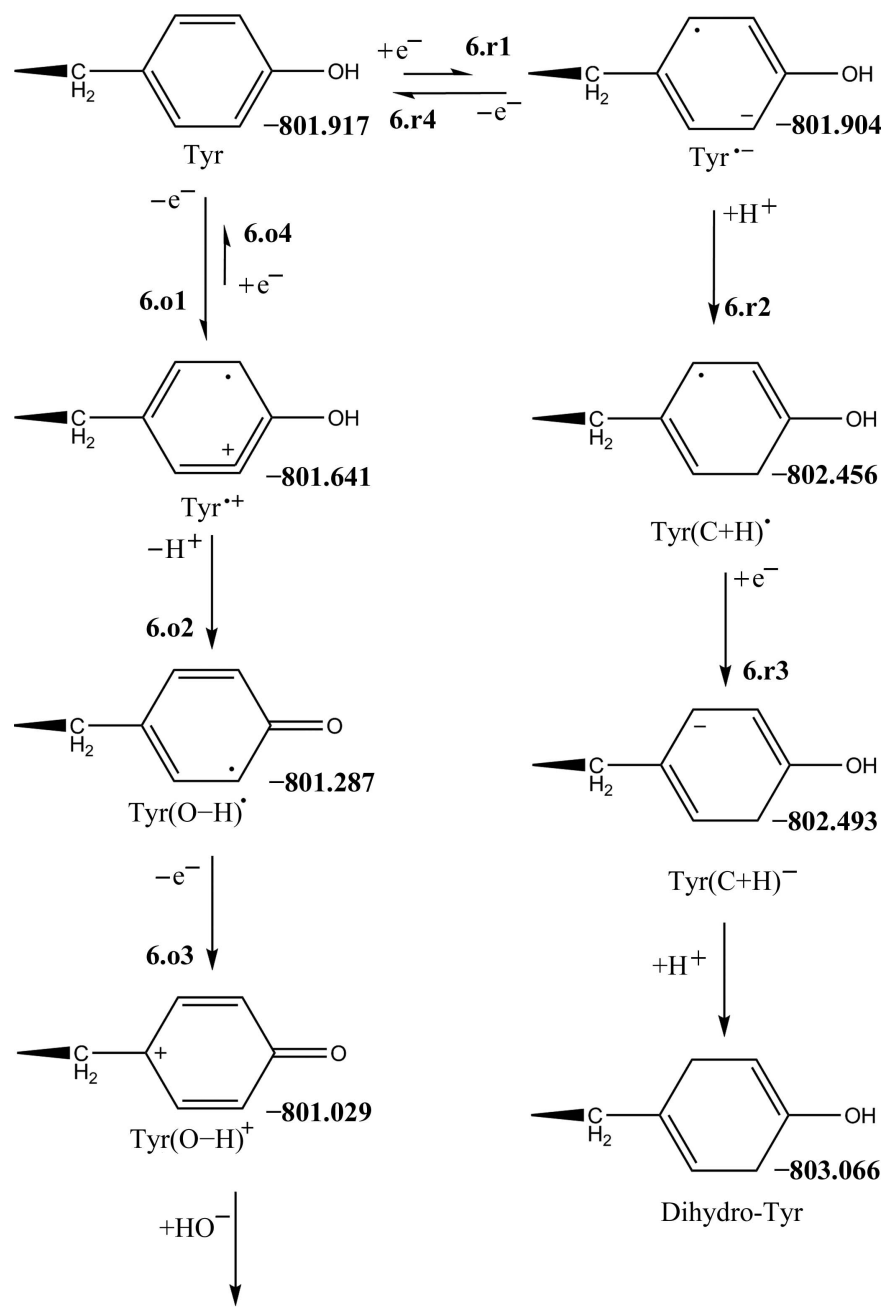

Dihydro-Tyr

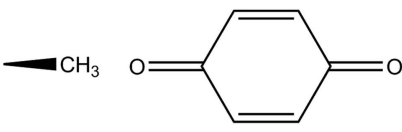

Ala 1,4-Benzoquinone

Figure 6

Reductive (left column) and oxidative (right column) reaction pathways for tyrosine. The reaction numbers are keyed to Fig. 1: the $\mathbf{6}$ in reaction 6.r1 refers to Fig. 6 and the $\mathbf{r} 1$ refers to reaction $\mathbf{r 1}$ of Fig. 1. The numbers in bold are the calculated energies of each species in units of hartrees. 
one-electron reduction yields an anion that has nearly the same energy as that of tyrosine, while the second one-electron reduction seems to be more thermodynamically advantageous (see Fig. 6). Further calculations are under way to examine the influence of different dielectric constants.

These results are important in understanding radiation damage to tyrosine in X-ray crystallography. It is known that clear electron-density loss is detectable in the region of Tyr $\mathrm{OH}$ groups, although no cleavage of the phenolic $\mathrm{C}-\mathrm{O}$ bond has been reported (Burmeister, 2000). This is in keeping with a calculation by Bury, Carmichael et al. (2016) that shows that the strength of the $\mathrm{C}-\mathrm{O}$ bond in tyrosine is approximately $110 \mathrm{kcal} \mathrm{mol}^{-1}$ and is not significantly different in the oxidized species. This leads to the supposition that the tyrosine ring undergoes a positional displacement (Bury, Carmichael et al., 2016).

As mentioned above, it is a stretch to use the oxidation pathway as an explanation for the crystallographic data suggesting loss of the $-\mathrm{OH}$ group. A more tenable explanation for the 'loss' of the $-\mathrm{OH}$ group is through the reduction pathway described above with two one-electron reductions to produce dihydrotyrosine. This partial saturation of the phenol ring may pucker the ring and would be likely to shift the position of the $-\mathrm{OH}$ group, which could amount to 'positional displacement of the tyrosine ring' as proposed by Bury, Carmichael et al. (2016). It is interesting to note that the calculations presented here indicate that neither the oxidation or reduction pathways include a reasonable mechanism for cleaving the $>\mathrm{C}-\mathrm{OH}$ bond.

In the paper by Bury and coworkers there is an interesting comment on the hydrogen-bond interactions of the Tyr $\mathrm{OH}$ and Glu/Asp carboxyl side groups (Bury, Carmichael et al., 2016). The present study does not involve calculations that include the influence of hydrogen bonding. Calculations are under way to do just that.

\subsection{Cysteine}

Cysteine is the second least abundant amino acid (less than $2 \%$ of all amino-acid residues in proteins). However, it has many important roles. Cysteine can stabilize proteins by forming disulfide bridges. It can also act as a radiation protector by scavenging $\mathrm{OH}^{\bullet}$ radicals, thereby preventing $\mathrm{OH}^{\bullet}$ radicals from damaging DNA, as in the reaction

$$
R \mathrm{SH}+\mathrm{OH}^{\bullet} \rightarrow \mathrm{RS}^{\bullet}+\mathrm{H}_{2} \mathrm{O} .
$$

Cysteine can also react with other radicals to limit DNA strand breaks, for example by $\mathrm{H}$-atom donation in the reaction

$$
\mathrm{DNA}^{\bullet}+R \mathrm{SH} \rightarrow \mathrm{DNA}+R \mathrm{~S}^{\bullet} .
$$

For more details, see Prakash Rao et al. (1992).

As in cystine, the oxidative pathway in cysteine is not expected to lead to cleavage of nonhydrogen covalent bonds, while the reductive pathway is. One-electron oxidation of cysteine thus produces the cysteine radical cation (7.o1), which will deprotonate to yield $\mathrm{Cys}(\mathrm{S}-\mathrm{H})^{\bullet}$. This radical has been reported by Akasaka (1965) and by Box et al. (1966), and exhibits a hyperfine spectrum of four lines owing to the two methylene protons (35.7 and 12.0 G). A second oxidation step is unlikely.

One-electron reduction of cysteine followed by protonation (7.r1 and 7.r2) gives $\mathrm{Cys}(\mathrm{S}+\mathrm{H})^{\bullet}$, as shown in 7.r2 in Fig. 7. This is an unstable intermediate, which can undergo unimolecular rearrangement (7.r6) resulting in cleavage of the $\mathrm{S}-\mathrm{C}$ bond to yield $\mathrm{SH}^{\bullet}$ and Ala (Garrison, 1987). Given that $1 \mathrm{ER}$ of $\mathrm{SH}^{\bullet}$ is highly favorable, as is protonation of $\mathrm{SH}^{-}$, the stable end products Ala and $\mathrm{SH}_{2}$ are predicted (Wilkening et al., 1968). If 1ER of $\mathrm{Cys}(\mathrm{S}+\mathrm{H})^{\bullet}$ occurs prior to the rearrangement, i.e. 7.r3 competes with 7.r6, then subsequent proton addition results in the same two end products.

Calculations began with just the cysteine side chain, as shown in Supplementary Fig. S7. It should be noted that the energies of the neutral molecule and the anion radical are nearly the same. Thus, one expects some of the anion radicals to undergo a back-reaction returning to the original neutral molecule, while other anion radicals may subsequently protonate (7.r2) to form the neutral radical in Fig. 7. It can be seen in Supplementary Fig. S7(b) that the model involves a dipole-bound structure. This can easily transform into a valence-bound anion, as shown in Supplementary Fig. S7(c). Here, the dielectric constant $\varepsilon$ is 2.5 .

A second set of calculations were performed on the short peptide Ala-Cys-Ala. For this calculation all of the spin density is at the carboxyl end of the peptide. A third calculation was

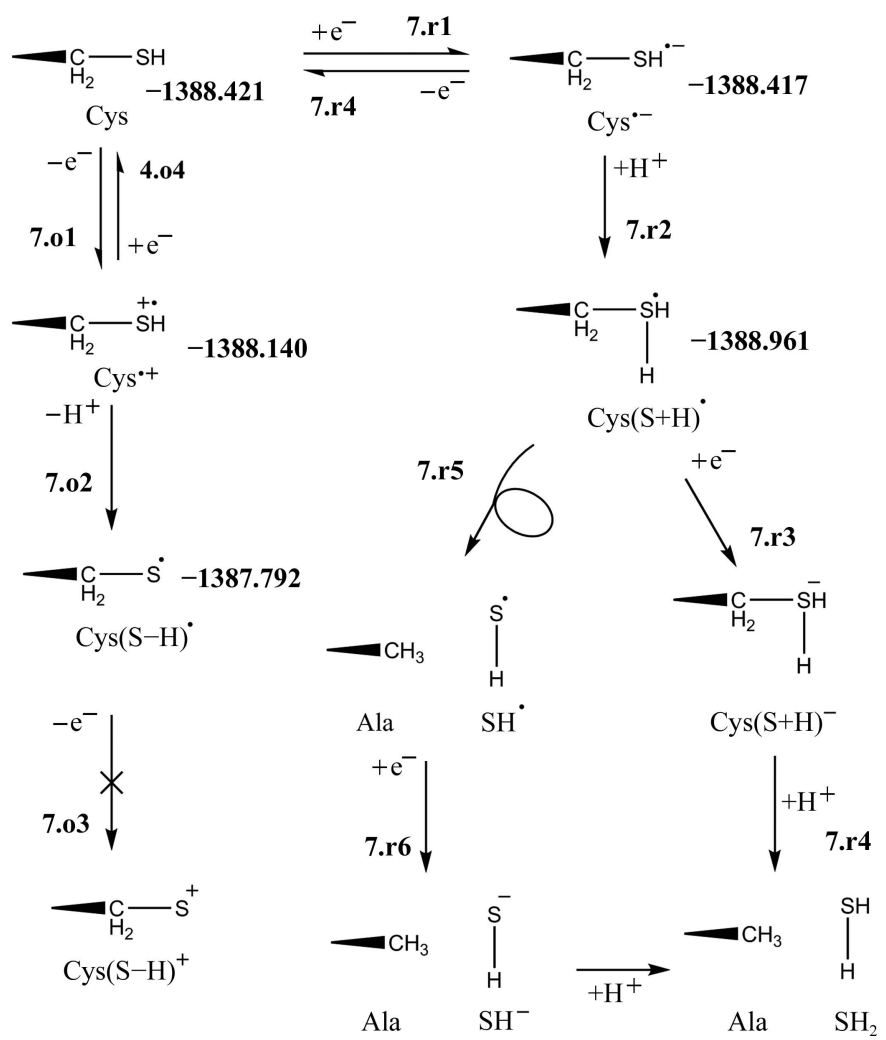

Figure 7

Reductive (right column) and oxidative (left column) reaction pathways for cysteine. The reaction numbers are keyed to Fig. 1: the 7 in reaction 7.r1 refers to Fig. 7 and the $\mathbf{r} 1$ refers to reaction $\mathbf{r} 1$ of Fig. 1. The numbers in bold are the calculated energies of each species in units of hartrees. 
performed on the slightly longer peptide model, as shown in Supplementary Fig. S8(a). Here, the spin density is partly on the cysteine side chain and mostly on the peptide backbone nearest to the side chain. This is a rather busy picture as one has to rotate the structure in order to see just where the spin density is.

The next step involves the addition of $\mathrm{H}^{+}$to the cysteine anion radical. Calculations indicate that this radical is unstable and loses $\mathrm{SH}_{2}$ (Fig. 7), which leaves the radical on the $-\mathrm{CH}_{2}$, as seen in Supplementary Fig. S9.

One-electron reduction of cysteine (7.r1) followed by protonation (7.r2) gives $\mathrm{Cys}(\mathrm{S}+\mathrm{H})^{\bullet}$. The $\mathrm{Cys}(\mathrm{S}+\mathrm{H})^{\bullet}$ can undergo unimolecular rearrangement (7.r5) resulting in cleavage of the $\mathrm{S}-\mathrm{C}$ bond to yield $\mathrm{SH}^{\bullet}$ and Ala. One-electron reduction of $\mathrm{SH}^{\bullet}$ is favorable (7.r6) as is protonation to yield $\mathrm{SH}^{-}$that results in the stable end products yield $\mathrm{SH}_{2}$ and Ala. If one-electron reduction of $\mathrm{Cys}(\mathrm{S}+\mathrm{H})^{\bullet}$ occurs prior to the above rearrangement (7.r3) then subsequent proton addition results in the same two end products $\mathrm{SH}_{2}$ and Ala (7.r4).

Calculations were also performed on the oxidation of cysteine. It can be seen in Fig. 7 that the first two steps (7.o1 and 7.o2) are energetically feasible. There were problems, however, with calculation of the second one-electron oxidation step 7.o3. If the peptide backbone is not constrained then calculations show that the peptide rearranges so that there is proton transfer from the methylene group of the cysteine moiety to a nearby $>\mathrm{C}=\mathrm{O}$.

\subsection{Methionine}

The reactions stemming from methionine are similar to those from cysteine. One-electron oxidation (8.01) of DLmethionine at $77 \mathrm{~K}$ produces the radical cation, as described by Kominami (1972). The EPR spectrum involves hyperfine couplings to the methyl and methylene protons. It seems unlikely that the radical cation can undergo a second oneelectron oxidation.

On the reduction side, the unimolecular rearrangement that was discussed for cysteine (7.r6 in Fig. 7) is less likely for methionine. Therefore, the final reduction products are predicted to be methane plus a $-\mathrm{CH}_{2}-\mathrm{CH}_{2}-\mathrm{SH}$ residue (the side chain of homocysteine) and/or methanethiol plus a $-\mathrm{CH}_{2}-$ $\mathrm{CH}_{3}$ residue (the side chain of $\alpha$-aminobutyric acid) as proposed by Kopoldová et al. (1967). A review by Burmeister stated that the final products have been identified but the reactions are unknown (Burmeister, 2000). Therefore, it is tempting to try calculations on methionine to see which steps are likely to occur to form the final reduction products.

Calculations on the reduction of the methionine side chain produce the dipole-bound anion in Supplementary $\mathrm{S} 10(b)$. Attempts to convert this structure into a valence-bound anion result in separation of the $\mathrm{SCH}_{3}$ group, with the spin density left behind on the $-\mathrm{CH}_{3}-\mathrm{CH}_{2}$, as seen in Supplementary Fig. S10(c). This is not the same as for cysteine, where about half of the spin density remains on the hydrogen in the valence-bound state (Supplementary Fig. S8b).
The next step is to examine the radiation chemistry of the methionine side chain in a peptide. The first thing to note is that the energy of the anion radical is a little larger than that of the neutral structure. For the first step in the reduction, one sees that for the methionine anion radical there is a large dipole-bound anion on the sulfur $\mathrm{CH}_{3}$ (Supplementary Fig. S11b). An SMD calculation was then performed on this same anion radical with a dielectric constant of 2.5. This is sufficient to create the valence-bound structure in Supplementary Fig. S11(c), where most of the spin density is centered on the carbonyl at the amino-terminal end of the model peptide.

The radical anion will attract a proton that will be on the sulfur, creating a neutral radical (8.r2). This is shown in Supplementary Fig. S12. Supplementary Fig. S12(a) shows the model peptide with an additional proton on the sulfur. This $\mathrm{CH}_{3}$-SH is unstable and the methyl group dissociates (Supplementary Fig. S12b). It can be seen in Supplementary Fig. S12(c) that all of the spin density resides on the dissociated $\mathrm{CH}_{3}$.

Thus, returning to the reductive pathway for methionine it seems that after the first electron capture and then protonation the neutral radical $\mathrm{Met}(\mathrm{S}+\mathrm{H})^{\bullet}$ follows the left-hand side of the reductive pathway, creating $\mathrm{SH}-\mathrm{CH}_{2}-\mathrm{CH}_{2}$ and methane.

It seems that the smaller peptide model works with these calculations. The one drawback is that for the calculation on the reductive pathway the first step involves the radical anion, which ends up as a dipole-bound anion. This state is easily converted to a valence anion with an SMD calculation with $\varepsilon=$ 2.5. Other than this, the calculations proceed to show the experimentally observed products formed by two one-electron reductions. On the oxidation side there is a problem with step 8.03. Calculations on $\mathrm{Met}^{++}(\mathbf{8 . 0 3})$ resulted in the methylene nearest the sulfur deprotonating to the nearest $>\mathrm{C}=\mathrm{O}$ within just a few iterations. Basically the same interaction took place at this step in the oxidation pathway of cysteine (see above). This is rather expected and is the reason why there is an $\mathrm{X}$ on this reaction (Fig. 8). One really cannot have a positive charge on the sulfur. However, if an additional positive charge is placed there then the molecule would be a strong acid and would deprotonate.

\subsection{Peptide bond}

Knowledge of the various reductive and oxidative events in polypeptides comes from early studies on $N$-acetylglycine [which contains a -CO-NH-H $(R)$ - peptide linkage]. The EPR spectra of irradiated $N$-acetylglycine were very complicated. Box and coworkers found four radical species in single crystals of $N$-acetylglycine at $4.2 \mathrm{~K}$ (Box et al., 1972). In order to sort out the complicated spectra, it was necessary to use ENDOR, controlled warming experiments and deuterated $\mathrm{N}$-acetylglycine. The results show that one-electron oxidation results in $\mathrm{CH}_{3}$-CO-ND- ${ }^{-} \mathrm{CH}_{2}$ formed by decarboxylation of the primary radical cation. An EPR study of the reactions of electrons with peptides can be found in D'Arcy \& Sevilla (1979). 

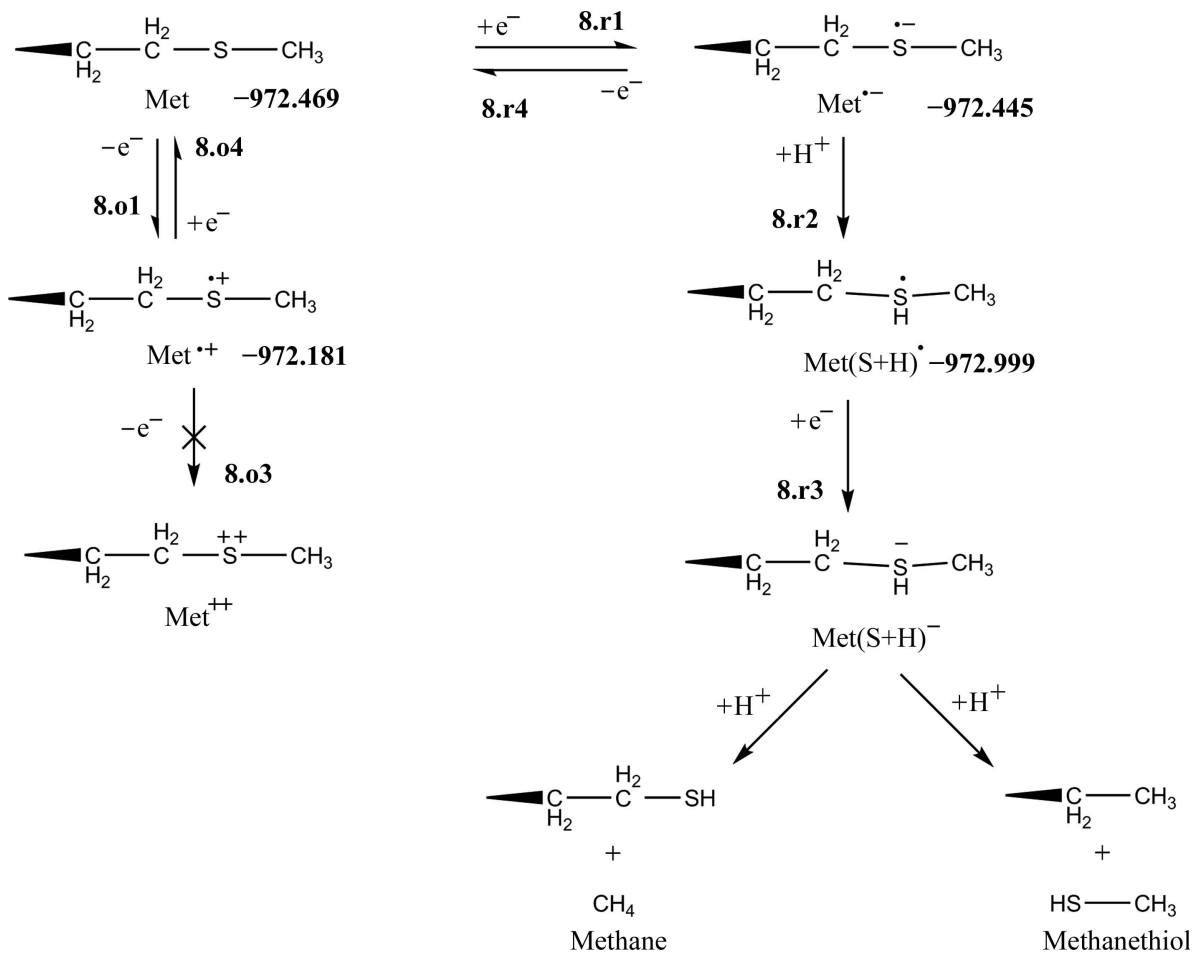

Figure 8

Reductive (right column) and oxidative (left column) reaction pathways for methionine. The reaction numbers are keyed to Fig. 1: the $\mathbf{8}$ in reaction 8.r1 refers to Fig. 8 and the r1 refers to reaction $\mathbf{r 1}$ of Fig. 1. The numbers in bold are the calculated energies of each species in units of hartrees.

Calculations were performed on both one-election reduction and one-electron oxidation of a peptide. The tripeptide model was chosen for these calculations. Supplementary Fig. S13 shows the steps in the one-electron reduction process. The model is simply Ala-Ala on the peptide backbone in Supplementary Fig. S13(a). From Fig. 9 it can be seen that the energy of the starting protein model is slightly higher than that of the radical anion. This means that some of the radical anions will revert to the starting model and some will be stabilized by protonation. This is followed by the radical anion [Supplementary Fig. S13(b)]. Here, one sees the majority of the spin density is at the amino-terminal end of the peptide. Supplementary Fig. S13(c) shows the neutral radical formed by protonation of the radical anion (protonation is at the central $>\mathrm{C}=\mathrm{O}$ ). Here, the majority of the spin density is on the central $>\mathrm{C}=\mathrm{O}$. The neutral radical could be further reduced to yield an anion. This anion will attract a proton to form the neutral $\mathrm{Pep}(\mathrm{O}+\mathrm{H}, \mathrm{C}+\mathrm{H})$. Calculations show that these last three steps involving a second one-electron reduction are energetically favorable (Fig. 9). Of particular interest here is that this forward reaction terminates in partial saturation of the peptide bond, but this does not break the backbone.

Moving to the oxidation of peptides (the left-hand side of Fig. 9), one-electron oxidation of the protein (9.01) produces a cation radical. It can be seen in Fig. 9 that this is energetically quite favorable. A picture of the spin density of the cation radical is shown in Supplementary Fig. $\mathrm{S} 14(b)$. This is rather interesting as there is some spin density on the entire molecule. This radical is stabilized by deprotonation.

On the oxidation side in Fig. 9, there is a branch as the deprotonation could occur on nitrogen or on carbon. It can be seen that this is energetically feasible for proton loss at the nitrogen (9.o2a). The spin density for this neutral radical is shown in Supplementary Fig. $\mathbf{S} 15(b)$. A second one-electron loss yields an unstable product, $\operatorname{Pep}(\mathrm{N}-\mathrm{H})^{\bullet}(\mathbf{9 . 0 3 a})$, which will cause a $\mathrm{C}-\mathrm{C}$ peptide-bond cleavage. After only a few iterations the energy is -742.215 hartree and the $\mathrm{C}$ $\mathrm{C}$ bond at the amino-terminal end of the peptide is already $1.64 \AA$.

The second path for deprotonation of the radical cation of a peptide involves deprotonation at a carbon and is shown to be energetically feasible (9.o2b). Sevilla and coworkers have shown that one-electron loss in peptides leads to carbon-centered radicals (Sevilla et al., 1979). Supplementary Fig. S15(d) shows the spin density for this neutral radical. It can be seen that most of the spin density is localized on the central $>\mathrm{C}=\mathrm{O}$ and the adjacent $\mathrm{HC}-\mathrm{CH}_{3}$. The next step involves a second one-electron oxidation, creating a cation, which is shown to be energetically feasible (Fig. 9). The last step involves an $\mathrm{OH}^{-}$ion. This reaction can be found in solution studies of amino acids, but in the present case of radiation damage in protein crystallography conducted at $100 \mathrm{~K}$ the $\mathrm{OH}^{-}$ion may not be able to move about.

The polypeptide structure of the protein backbone is predicted to be unique in its resistance to damage from the effects of ionizing radiation. A prominent feature of Fig. 9 is that for both the reductive and oxidative sides recombination of holes with excess electrons dominates. The back-reactions 9.04a, 9.o4b and 9.r4 are all expected to be favorable.

Furthermore, the forward reactions 9.o1-9.o2-9.03b and 9.r1-9.r2-9.r3 terminate in partial saturation of the peptide bond but do not break the backbone. It is conceivable that this structure arose under evolutionary pressure owing to high radiation fluence during abiogenesis.

\section{Progress in understanding radiation damage during macromolecular X-ray crystallographic data collection}

This short summary involves the supposition that two oneelectron reductions/oxidations can be used to explain the observed products at high doses that are present in macromolecular X-ray crystallography.

In the dose range of tens of kilograys, damage to the crystals consists of one-electron reductions and one-electron oxidations; with the exceptions of Glu and Asp, these are small 
(negligible) perturbations on the diffraction data. In the dose range of tens of megagrays, damage owing to multiple tracks increases linearly with dose (at low doses the dependence is quadratic; Swarts et al., 2007).

Deep traps for the excess electron are relatively scarce, whereas they are abundant for the hole. The deepest electron trap is cystine, followed by Cys, Met, Asp, Glu and the aromatics. One-electron reductions of these sites are minor 'perturbations' on the diffraction data. The data are being collected from proteins with a large fraction of these sites oneelectron reduced; i.e. the bond lengths should be longer than those found for simple amino acids, where data are collected at much lower doses.

Proton transfer accompanies nearly all of the reactions that carry the initial radical ions forward to stable end products. These are thermodynamically driven by two factors: (i) the change in effective $\mathrm{p} K_{\mathrm{a}}$ when an electron is either added or removed and (ii) the proton-donating and proton-accepting ability of the immediate environment. Also, protons released by ionizing radiation will add to neighboring sites before or after electron addition. In either case, for protons adding before or after, at least two overlapping traps would be required to push the two oneelectron reduction reactions forward to product.

Protonation of one-electron reduced $R \mathrm{SSR}, \mathrm{RSH}$ and $\mathrm{RSCH}_{3}$ results in a type of radical that is in itself a good electron trap. Thus, at higher doses a second one-electron reduction is likely. When this happens, strong covalent bonds break: the $\mathrm{S}-\mathrm{S}$ and $\mathrm{S}-\mathrm{C}$ bond, respectively. This results in loss of electron density at these sites.

The key concepts are quite similar for the one-electron oxidized sites, but the impact is not nearly as specific. This is because every peptide bond is a good hole trap. Some residues, for example Tyr and Glu, are also good hole traps, but the concentration of the competing backbone sites (peptide bonds) will typically be approximately a hundred times greater. Thus, the backbone protects the residues from oxidation.

Competing with the forward processes that entail two reductions or two oxidations are the backward processes that bring the hole and electron back together. These recombination reactions are the dominant reaction.

\section{Conclusions}

This study was undertaken to obtain a better understanding of free-radical formation as well as free-radical destruction that may be influential in obtaining X-ray diffraction data. We already know the types of damage that a protein crystal suffers. 'Firstly

Reductive (right column) and oxidative (left column) reaction pathways for the peptide bond. The reaction numbers are keyed to Fig. 1: the $\mathbf{9}$ in reaction $\mathbf{9 . r 1}$ refers to Fig. 9 and the r1 refers to reaction r1 of Fig. 1. The numbers in bold are the calculated energies of each species in units of hartrees. 
disulfide bridges elongate and then break, secondly glutamates and aspartates are decarboxylated, thirdly tyrosine residues lose their hydroxyl group, and fourthly, the carbonsulfur bond of methionines are cleaved' (Sutton et al., 2013). Note that the present study shows that tyrosine does not actually lose its hydroxyl group, as previously suggested by Bury, Carmichael et al. (2016). The present study was undertaken to see the steps necessary to form the observed products. In cases where there were multiple pathways, highlevel calculations were used to see which pathways were energetically feasible.

Some highlights of this study involve multiple problems with dipole-bound anions. These occurred in calculations in vacuum. It was shown that performing calculations in a dielectric medium converted the dipole-bound anions to valence-bound anions. There are obviously other needs for such calculations. Crystallographers are fond of the phrase 'effect of local environment' and there are plenty of examples. In the lysozyme study it was noted that disulfide-bond cleavage depends on the local environment (Sutton et al., 2013). It seems that different Cys-Cys bonds have different solvent accessibilities. Indeed, it seems 'that damage susceptibility within each residue type follows a preferential ordering influenced by a combination of local environment factors (solvent accessibility, conformational strain and proximity to active sites)' (Bury, MeGeehan et al., 2016). The study of the interplay of all of these various factors is amenable to highlevel calculations. For example, in Section 3 above it was mentioned that dipole-bound anions can be converted to valence-bound anions by switching from the gas phase $(\varepsilon=$ 1.0) to the solution phase $(\varepsilon=80.0)$ (Puiatti et al., 2008). It has been shown here that this switchover can actually occur at $\varepsilon=$ 2.5. Calculations are in progress to examine the 'effect of local environment' by varying the dielectric constant in small steps from $\varepsilon=2.5$ to $\varepsilon=80.0$.

\section{Acknowledgements}

Much of this material covers work performed in collaboration with Professor William Bernhard at the University of Rochester. He chaired a section of the Radiation Chemistry 2008 Gordon Research Conference and was instrumental in seeing that the conference included an X-ray Studies section with Discussion Leader Elspeth Garman (Oxford University) and speakers Lin Chen (Northwestern University) and Edward Snell (Hauptman-Woodward Medical Research Institute). As there is plenty of free time at a Gordon Conference, there were afternoon discussions on future collaborations. Edward Snell's graduate student Kristin Sutton had a chapter in her thesis entitled $A$ Generalized Model for Radiation Damage of Amino Acids Based on Multi-Track Model Predictions. This work included Bernhard's schemes on the reductive and oxidative reaction pathways of the various amino acids. This thesis also included an important section Agreement with the Model and Experimental Results. This work was published in Acta Crystallographica Section D (Sutton et al., 2013). I volunteered to look into performing calculations involving two sequential one-electron oxidations/reductions. The first study involved a Journal of Physical Chemistry A publication (Close et al., 2013). Unfortunately, William Bernhard died in May 2012. An In Memoriam summarizing his work appeared in Radiation Research (Close et al., 2012). I hesitated in starting the present study as I only had a rough draft of Bernhard's manuscript. The draft did not have any references. It took some time to find suitable references, but I have no idea whether some of these were the references that Bernhard intended. The Gaussian 09 calculations reported here were supported by the Extreme Science and Engineering Discovery Environment (XSEDE). Many thanks to Mahidhar Tatineni at San Diego Supercomputer Center for much help with the calculations on Comet.

\section{Funding information}

The calculations presented here were supported by the Extreme Science and Engineering Discovery Environment (XSEDE) allocation number MCB150023. Thanks for the generous computer time allocation (to DMC) to complete this project.

\section{References}

Adams, S. M., Budzinski, E. E. \& Box, H. C. (1976). J. Chem. Phys. 65, 998-1001.

Akasaka, K. (1965). J. Chem. Phys. 43, 1182-1184.

Akasaka, K., Ohnishi, S.-I., Suita, T. \& Nitta, I. (1964). J. Chem. Phys. 40, 3110-3116.

Becker, D., Swarts, S., Champagne, M. \& Sevilla, M. D. (1988). Int. J. Radiat. Biol. 53, 767-786.

Bernhard, W. A. \& Close, D. M. (2003). Charged Particle and Photon Interactions with Matter, edited by A. Mozumder \& Y. Hatano, pp. 471-489. New York: Marcel Dekker.

Bonifačić, M. \& Asmus, K.-D. (1978). J. Phys. Chem. 80, 2426-2430.

Box, H. C., Budzinski, E. E. \& Freund, H. G. (1974). J. Chem. Phys. 61, 2222-2226.

Box, H. C., Budzinski, E. E. \& Lilga, K. T. (1972). J. Chem. Phys. 57, 4295-4298.

Box, H. C. \& Freund, H. G. (1964). J. Chem. Phys. 41, 2571.

Box, H. C., Freund, H. G. \& Budzinski, E. E. (1966). J. Chem. Phys. 45, 809-811.

Box, H. C., Freund, H. G., Lilga, K. T. \& Budzinski, E. E. (1970). J. Phys. Chem. 74, 40-52.

Burmeister, W. P. (2000). Acta Cryst. D56, 328-341.

Bury, C. S., Carmichael, I. \& Garman, E. F. (2017). J. Synchrotron Rad. 24, 7-18.

Bury, C. S., McGeehan, J. E., Antson, A. A., Carmichael, I., Gerstel, M., Shevtsov, M. B. \& Garman, E. F. (2016). Acta Cryst. D72, 648657.

Carpentier, P., Royant, A., Weik, M. \& Bourgeois, D. (2010). Structure, 18, 1410-1419.

Carugo, O. \& Djinović Carugo, K. (2005). Trends Biochem. Sci. 30, 213-219.

Chan, P. C. \& Bielski, B. H. J. (1973). J. Am. Chem. Soc. 95, 55045508.

Close, D. M., Nelson, W. H. \& Bernhard, W. A. (2013). J. Phys. Chem. A, 117, 12608-12615.

Close, D. M., Sevilla, M. D. \& Coleman, N. (2012). Radiat. Res. 178, 101-103.

Close, D. M. \& Wardman, P. (2018). J. Phys. Chem. A, 122, 439-445. D'Arcy, J. B. \& Sevilla, M. D. (1979). Radiat. Phys. Chem. 13, 119-126. 
Frisch, M. J., Trucks, G. W., Schlegel, H. B., Scuseria, G. E., Robb, M. A., Cheeseman, J. R., Scalmani, G., Barone, V., Mennucci, B., Petersson, G. A., Nakatsuji, H., Caricato, M., Li, X., Hratchian, H. P., Izmaylov, A. F., Bloino, J., Zheng, G., Sonnenberg, J. L., Hada, M., Ehara, M., Toyota, K., Fukuda, R., Hasegawa, J., Ishida, M., Nakajima, T., Honda, Y., Kitao, O., Nakai, H., Vreven, T., Montgomery, J. A. Jr, Peralta, J. E., Ogliaro, F., Bearpark, M., Heyd, J. J., Brothers, E., Kudin, K. N., Staroverov, V. N., Kobayashi, R., Normand, J., Raghavachari, K., Rendell, A., Burant, J. C., Iyengar, S. S., Tomasi, J., Cossi, M., Rega, N., Millam, J. M., Klene, M., Knox, J. E., Cross, J. B., Bakken, V., Adamo, C., Jaramillo, J., Gomperts, R., Stratmann, R. E., Yazyev, O., Austin, A. J., Cammi, R., Pomelli, C., Ochterski, J. W., Martin, R. L., Morokuma, K., Zakrzewski, V. G., Voth, G. A., Salvador, P., Dannenberg, J. J., Dapprich, S., Daniels, A. D., Farkas, O., Foresman, J. B., Ortiz, J. V., Cioslowski, J. \& Fox, D. J. (2013). Gaussian 09. Gaussian Inc., Wallingford, Connecticut, USA.

Garrison, W. M. (1987). Chem. Rev. 87, 381-398.

Gonnelli, M. \& Strambini, G. B. (2005). Photochem. Photobiol. 81, 614-622.

Hidaka, H., Horikoshi, S., Ajisaka, K., Zhao, J. \& Serpone, N. (1997). J. Photochem. Photobiol. Chem. 108, 197-205.

Kang, H., Jouvet, C., Dedonder-Lardeux, C., Martrenchard, S., Grégoire, G., Desfrançois, C., Schermann, J.-P., Barat, M. \& Fayeton, J. A. (2005). Phys. Chem. Chem. Phys. 7, 394-398.

Kleinermanns, K., Nachtigallová, D. \& de Vries, M. S. (2013). Int. Rev. Phys. Chem. 32, 308-342.

Kominami, S. (1972). J. Phys. Chem. 76, 1729-1733.

Kopoldová, J., Liebster, J. \& Gross, E. (1967). Radiat. Res. 30, 261274.

Lee, D., Furche, F. \& Burke, K. (2010). J. Phys. Chem. Lett. 1, 2124 2129.

Lipfert, J., Llano, J. \& Eriksson, L. A. (2004). J. Phys. Chem. B, 108, 8036-8042.

Marenich, A. V., Cramer, C. J. \& Truhlar, D. G. (2009). J. Phys. Chem. $B, \mathbf{1 1 3}, 6378-6396$.

Mezzetti, A., Maniero, A. L., Brustolon, M., Giacometti, G. \& Brunel, L. C. (1999). J. Phys. Chem. A, 103, 9636-9643.
Naito, A., Akasaka, K. \& Hatano, H. (1976). J. Magn. Reson. 24, 5362.

$\varnothing$ yen, L. F., Aalbergsj $\varnothing$, S. G., Knudtsen, I. S., Hole, E. O. \& Sagstuen, E. (2014). J. Phys. Chem. B, 119, 491-502.

Prakash Rao, P. J., Bothe, E. \& Schulte-Frohlinde, D. (1992). Int. J. Radiat. Biol. 61, 577-591.

Psciuk, B. T., Lord, R. L., Munk, B. H. \& Schlegel, H. B. (2012). J. Chem. Theory Comput. 8, 5107-5123.

Puiatti, M. D. M., Vera, A. \& Pierini, A. B. (2008). Phys. Chem. Chem. Phys. 10, 1394-1399.

Ravelli, R. B. G. \& Garman, E. F. (2006). Curr. Opin. Struct. Biol. 16, 624-629.

Ravelli, R. B. G. \& McSweeney, S. M. (2000). Structure, 8, 315-328.

Sagstuen, E., Close, D. M., Vågane, R., Hole, E. O. \& Nelson, W. H. (2006). J. Phys. Chem. A, 110, 8653-8662.

Sagstuen, E., Sanderud, A. \& Hole, E. O. (2004). Radiat. Res. 162, 112-119.

Sevilla, M. D. \& D'Arcy, J. B. (1978). J. Phys. Chem. 82, 338-342.

Sevilla, M. D., D'Arcy, J. B. \& Morehouse, K. M. (1979). J. Phys. Chem. 83, 2887-2892.

Steinrauf, L. K., Peterson, J. \& Jensen, L. H. (1958). J. Am. Chem. Soc. 80, 3835-3838.

Strzelczak, G., Bergès, J., Houée-Levin, C., Pogocki, D. \& Bobrowski, K. (2007). Biophys. Chem. 125, 92-103.

Sutton, K. A. (2013). Thesis. University of Buffalo, USA.

Sutton, K. A., Black, P. J., Mercer, K. R., Garman, E. F., Owen, R. L., Snell, E. H. \& Bernhard, W. A. (2013). Acta Cryst. D69, 23812394.

Svozil, D., Frigato, T., Havlas, Z. \& Jungwirth, P. (2005). Phys. Chem. Chem. Phys. 7, 840-845.

Swarts, S. G., Gilbert, D. C., Sharma, K. K., Razskazovskiy, Y., Purkayastha, S., Naumenko, K. A. \& Bernhard, W. A. (2007). Radiat. Res. 168, 367-381.

Verdolino, V., Cammi, R., Munk, B. H. \& Schlegel, H. B. (2008). J. Phys. Chem. B, 112, 16860-16873.

Wardman, P. \& von Sonntag, C. (1995). Methods Enzymol. 251, 31-45.

Wilkening, V. G., Lal, M., Arends, M. \& Armstrong, D. A. (1968). J. Phys. Chem. 72, 185-190. 